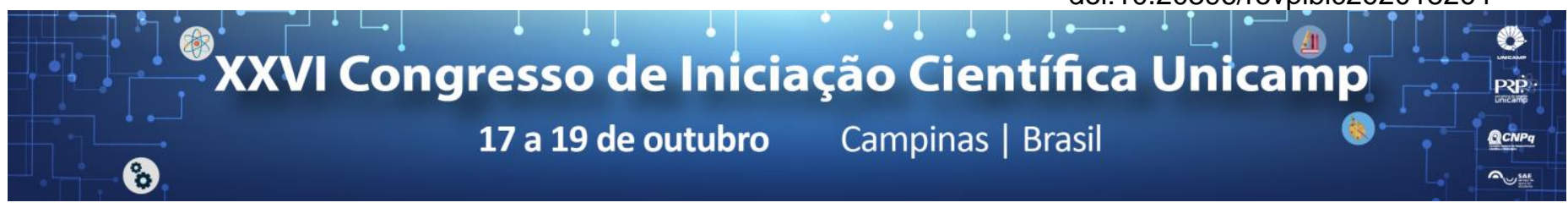

\title{
Modelagem no ABAQUS para análise do impacto do uso de ligas com memória de forma (SMA) em isoladores sísmicos
}

\section{Camila Santos Bergamo*, Gustavo Henrique Siqueira.}

\section{Resumo}

A eficiência do uso de isoladores sísmicos está no fato de que eles permitem que os movimentos da superestrutura e subestrutura ocorram de forma isolada [1], sendo a energia dissipada no isolador e reduzindo as forças laterais aplicadas à subestrutura. Dentre todas as propriedades mecânicas, a mais desejada para os materiais hiperelásticos utilizados em estruturas civis, como a borracha natural, é a sua capacidade de sofrer grandes deformações em regime elástico [2]. A pesquisa em pauta visa à introdução de conhecimentos básicos inerentes à metodologia cientifica e ao comportamento dinâmico de estruturas civis, assim como a introdução às técnicas de avaliação do comportamento dinâmico de estruturas a partir da modelagem através do método de elementos finitos. Também levanta o estudo de Shape Memory Alloys (materiais com propriedades hiperelásticas) e como suas propriedades podem ser utilizadas em isoladores sísmicos de borracha natural. Para tanto, resultados experimentais obtidos por Siqueira e col. [3] foram utilizados na calibração de um modelo em elementos finitos no Abaqus [4]. Posteriormente foram aplicados cabos de Shape Memory Alloys, de modo a avaliar mudanças no comportamento mecânico de um isolador de borracha natural quando esse material é adicionado.

\section{Palavras-chave:}

Simulação numérica, Isoladores sísmicos, Shape memory alloys.

\section{Introdução}

Esse projeto propõe o estudo da substituição do tipicamente utilizado aparelho de apoio convencional com material elastomérico, por dispositivos isoladores sísmicos em borracha natural, em razão de sua maior resistência a tensões de cisalhamento e a climas frios como o do Canadá [5]. Para tanto, um modelo foi calibrado com base em resultados de experimentos realizados em isoladores retangulares com diferentes tamanhos e fatores de forma [3].

Inseriu-se em conjunto com a borracha natural algumas configurações de cabos feitos de ligas com memórias, os Shape Memory Alloys (SMA), de forma de modo a avaliar as alterações mecânicas no conjunto. Caracterizados por suas propriedades hiperelásticas de centralização, os SMA vêm sendo adotados no controle de estruturas sujeitas a abalos sísmicos, caso em que as propriedades histeréticas do material acabam por ter um papel importante na determinação da resposta da estrutura. Suas propriedades termomecânicas únicas permitem-no retornar à sua forma original se aquecido ou sob a remoção das tensões aplicadas, sendo utilizado em cabos de contraventamento transversal, amortecedores de controle passivo, conexões em aço para restrição de momento e reforço de pontes contra terremotos [6].

\section{Resultados e Discussão}

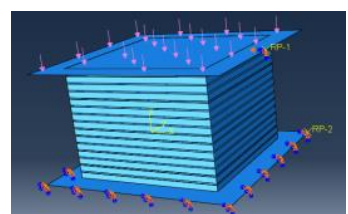

Figura 1: Modelo desenhado no Abaqus para calibração e realização dos testes.
O modelo de isolador sísmico foi criado no Abaqus, como demonstra a figura 1, e depois de calibrado (ou seja, de obtida uma curva semelhante à experimental gerada por Siqueira e col.), adicionou-se cabos de ligas com memória de forma, como demonstra a figura 2.

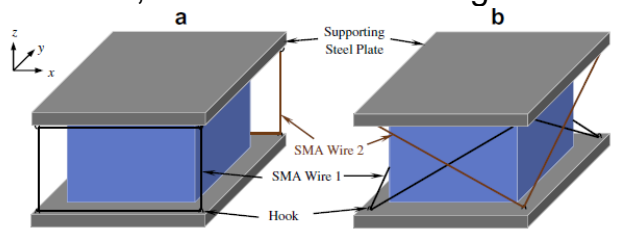

Figura 2: Isolador sísmico com cabos de SMAs retos e em "X" (fonte: Desfuli e Alam [12])

\section{Conclusões}

Existe, assim, a possibilidade de melhoria das propriedades de isoladores com a adição de ligas com memória de forma, como aqui demonstrado.

\section{Agradecimentos}

Instituição de fomento PIBIC/CNPq

${ }^{1}$ Chaudhary MTA, Abe M, Fujino Y, Yoshida J. System identification and performance evaluation of two base-isolated bridges using seismic records. Journal of Structural Engineering Publications, 2000.

${ }^{2}$ Shahzad M. Mechanical Characterization and FE Modeling of a Hyperelastic Material. Materials Research, 2015.

${ }^{3}$ Siqueira, G H., Sanda, A. S., Paultre, P. Padgett, J. E. Fragility curves for isolated bridges in eastern Canada using experimental results. Engineering Structures, vol. 74 (1), pp. 311-324, 2014.

${ }^{4}$ WROUGHT PLAIN CARBON STEEL. (2017). MakeItFrom. Disponível em $<$ https://www.makeitfrom.com/material-properties/ASTM-A36-SS400-S275-

Structural-Carbon-Steel>. Acesso em: 5 nov. 2017.

${ }^{5}$ Siqueira, G H., Tavares, D. H., Paultre, P. Padgett, J. E. Performance evaluation of natural rubber seismic isolators as a retrofit measure for typical multi-span concrete bridges in eastern Canada. Engineering Structures, vol. 74 (1), pp. 300-310, 2014.

${ }^{6}$ Andrawes, B., DesRoches, R. Effect of hysteretic properties of superelastic shape memory alloys on the seismic performance of structures. Structural Control and Health Monitoring, 2006. 